\title{
ATELIÊS DE PROJETO DE DESIGN E DE ARQUITETURA: ESPAÇO, ENSINO E SUAS CORRELAÇÕES
}

\author{
ATELIÉS DE PROYECTO DE DISEÑO Y DE ARQUITECTURA: ESPACIO, ENSEÑANZA Y SUS \\ CORRELACIONES
}

\section{DESIGN AND ARCHITECTURE STUDIOS: SPACE, TEACHING AND THEIR CORRELATIONS}

\section{LEITE, IZABEL FARIAS BATISTA}

Arquiteta e Urbanista. Mestre em Design pela Universidade Federal de Campina Grande (UFCG) - PB; izabelfbl@gmail.com.

\section{SILVA, HEITOR DE ANDRADE}

Arquiteto e Urbanista. Doutor. Professor da Universidade Federal do Rio Grande do Norte (UFRN) - Curso de Arquitetura e Urbanismo; heitor.andrade@ufrn.abea.arq.br.

\begin{abstract}
RESUMO
Os cursos de graduação em Design e em Arquitetura e Urbanismo utilizam como alicerce para o processo de ensino-aprendizagem os ateliês, a partir dos quais os alunos aprendem fazendo, praticando e desenvolvendo as atividades de projeto. Deste modo, estes precisam, enquanto espaço de síntese, agregar as condições necessárias para se tornar um ambiente de construção, oportunizando a interação e a diversidade de possibilidades de fruição e aproveitamento dos seus recintos: professor e aluno, escola e comunidade, em um processo reflexivo e buscando o real aprendizado amparado na instrução. A temática principal trabalhada no artigo se refere ao ensino de projeto nos ateliês e, para isso, acredita-se que a questão metodológica e pedagógica, bem como sua relação com a infraestrutura disponibilizada em tais espaços, é fundamental para entender, a partir da perspectiva dos docentes e discentes, especificidades e particularidades sobre a temática. Nesse sentido, o artigo apresenta dados obtidos em um estudo de caso realizado nos ateliês do curso de Design e de Arquitetura e Urbanismo da Universidade Federal de Campina Grande (UFCG), que permitiram a visualização das estratégias de ensino adotadas pelos docentes; dos processos avaliativos e de aspectos referentes a relação entre professor e aluno.
\end{abstract}

PALAVRAS-CHAVE: Ensino de Design. Ensino de Arquitetura. Ensino de projeto. Ateliê de projeto.

\section{RESUMEN}

Los cursos de graduación en Diseño y en Arquitectura y Urbanismo utilizan como base para el proceso de enseñanza-aprendizaje los ateliés, a partir de los cuales los alumnos aprenden haciendo, practicando y desarrollando las actividades de proyecto. De este modo, estos necesitan, como espacio de sintesis, agregar las condiciones necesarias para convertirse en un ambiente de construcción, oportunizando la interacción y la diversidad de posibilidades de fruición y aprovechamiento de sus recintos: profesor y alumno, escuela y comunidad, en un proceso reflexivo y buscando el real aprendizaje amparado en la instrucción. La temática principal trabajada en el artículo se refiere a la enseñanza de proyecto en los ateliés y, para ello, se cree que la cuestión metodológica y pedagógica, así como su relación con la infraestructura puesta a disposición en tales espacios es fundamental para entender, desde la perspectiva de los ciudadanos, docentes y discentes, especificidades y particularidades sobre la temática. En este sentido, el artículo presenta datos obtenidos en un estudio de caso realizado en los ateliés del curso de Diseño y de Arquitectura y Urbanismo de la Universidad Federal de Campina Grande (UFCG), que permitieron la visualización de las estrategias de enseñanza adoptadas por los docentes; de los procesos evaluativos y de aspectos referentes a la relación entre profesor y estudiante.

PALAVRAS-CLAVES: Enseñanza de Diseño. Enseñanza de Arquitectura. Enseñanza de proyecto. Ateliés de proyecto.

\section{ABSTRACT}

The undergraduate courses in Design and Architecture and Urbanism use as a foundation for the teaching-learning process the studios, which students learn by executing, practicing and developing project activities. In this way, they need, as a synthesis space, to add the necessary conditions to become a construction environment, allowing the interaction and the diversity of possibilities of enjoyment and use of its enclosures: teacher and student, school and community, in a process reflective and seeking real learning based on instruction. The main theme in the article refers to the teaching of project in the ateliers and, for this, it is believed that the methodological and pedagogical question, as well as its relation with the infrastructure made available in such spaces is fundamental to understand, from the perspective of the teachers and students, specificities and particularities on the subject. In this sense, the article presents data obtained in a case study carried out in the workshops of Design and Architecture and Urbanism of the Federal University of Campina Grande (UFCG), which allowed the visualization of the teaching strategies adopted by the teachers; evaluation processes and aspects related to teacher and student relationship.

KEYWORDS: Design Teaching. Architecture Teaching. Project Teaching. Design Studio. 


\section{INTRODUÇÃO}

De acordo com Lawson (2011), tradicionalmente e historicamente, as escolas de arquitetura e de design utilizam o ateliê como principal estratégia de ensino, baseando-se no "aprender fazendo" a partir de um determinado problema de projeto. A ideia é compartilhada por diversos outros autores, a exemplo de Schön (2000), Rheingantz (2003) e Chupin (2003).

O projeto, por sua vez, configura-se como uma atividade comum e essencial para a arquitetura e para o design, pois ambos os campos disciplinares o utilizam como forma de discussão do objeto, como um instrumento de linguagem, um registro de algo que pode ser materializado, seja um produto (design) ou uma edificação (arquitetura). Isso se reflete no âmbito acadêmico por meio de estruturas curriculares que adotam o ateliê como "espinha dorsal" dos cursos de graduação em Arquitetura e em Design (Figura 1). No entanto, o adequado desenvolvimento de um projeto no ambiente acadêmico demanda ateliês coerentes, isto é, que atendam às demandas de qualidade físico-estruturais, aspecto que deve ser reconhecido nos Projetos Político Pedagógicos e refletido nas estruturas curriculares dos cursos. Sob essa abordagem mais ampla, que envolve o ensino de arquitetura, de design e o ensino de projeto, acrescentam-se as noções mais progressistas do processo de aprendizagem, segundo as quais o espaço do ateliê de projeto assume um papel primordial no debate, sendo considerado como um ambiente de síntese e componente estruturante dos Projetos Político Pedagógicos.

Diante deste contexto, este artigo, fruto de uma pesquisa de mestrado que foi motivada pela inquietação dos pesquisadores relacionada à caracterização (espaço físico disponibilizado, metodologias e estratégias pedagógicas utilizadas) dos ateliês de projeto considerando o sistema universitário no qual estão inseridos, tem como foco o ensino de projeto nos ateliês de um caso estudado. Para tanto, fez-se necessária a análise de alguns componentes curriculares para que houvesse uma maior aproximação com as questões inerentes à temática. Deste modo, foram selecionadas três disciplinas de projeto do curso de Arquitetura e Urbanismo e mais três do curso de Design, todas ofertadas na Universidade Federal de Campina Grande (UFCG).

Figura 1: Relação do projeto com o Design e a Arquitetura e Urbanismo.

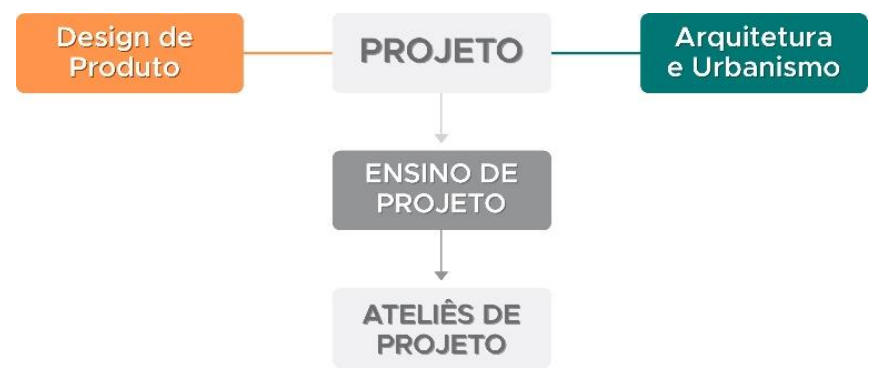

Fonte: Acervo dos autores, 2017.

Aspectos relativos às estratégias pedagógicas utilizadas pelos docentes para facilitar o aprendizado, as formas de avaliação e a relação entre professor e aluno foram analisados a partir de três instrumentos (ficha de observação, questionário e entrevista semiestruturada), os quais eram compostos de dois eixos principais que posteriormente foram correlacionados, quais sejam infraestrutura do ateliê e o ensino de projeto.

\section{O PROJETO: CONCEITO, ENSINO E ATELIÊ}

O termo "projeto" comporta diversos significados, que podem, inclusive, não estar ligados ao design ou à arquitetura, uma vez que o mesmo está relacionado a vários campos da ação humana, a exemplo da antropologia, psicologia, ambiente acadêmico (objeto da pesquisa) e profissional, bem como, situações corriqueiras da vida cotidiana (SILVA, 2012). Nesse sentido, Chupin (2003) defende que o projetar pode e é feito em vários outros setores da atividade humana, no entanto, cada campo tem especificidades que devem ser respeitadas. Todavia, apesar da amplitude semântica do termo, Silva (2012) sugere um conceito para o projeto que remete à antecipação das ações, ou seja, através da elaboração de um plano de metas e estratégias que visam a atingir um objetivo, o projeto auxilia na obtenção dos desejos do usuário, antecipando as ações do registro. Segundo o autor, é uma atividade que demanda habilidades como o raciocínio lógico, a percepção espacial, a criatividade, dentre outras.

De forma complementar, Boutinet (2002, p.27) afirma que: 
O projeto pode ser definido como conceito dotado de propriedades lógicas a serem explicitadas em suas conexões com a ação a ser conduzida. Mas, ao mesmo tempo, o projeto aparece como figura que remete a um paradigma, simbolizando uma realidade que parece preexistir e escapar-nos: aquela de uma capacidade a ser criada, de uma mudança a ser operada.

Assim, o projeto pode ser entendido como uma sistematização de dados e ideias e somente deixa de ser projeto quando sua concretização já apresenta o objeto em sua configuração definitiva. No âmbito da arquitetura, o projeto aparece como um processo construtivo e, sendo assim, torna-se difícil o arquiteto fazer uso apenas de esperança e determinação para concretizá-lo, principalmente porque é necessário, na grande maioria das vezes, conhecimentos específicos para solucionar determinado problema. Piñón (2006, p.210) resume essa noção quando diz que "no caso da arquitetura, o projeto é o instrumento de ação ordenadora, isto é, da construção da forma".

O projeto em design, segundo Ferrara (2002), está relacionado, em sua essência, a uma intenção, um plano, desígnio ou a uma prática. Também pode ser interpretado como um fazer que tem como resultado um produto, uma informação nova e a proposição de novos valores. Silva (2009) defende que o projeto no campo do design requer atenção para que a competência do "saber fazer" possa ser transformada no "saber por que faz". A autora enfatiza que o "fazer" deve estar sempre pautado nos caminhos inventivos para que o produto seja o mais inovador possível. Para Redig $(2005, \mathrm{~s} / \mathrm{p})$, o projeto é um componente de investigação que antecede a criação, "é um trabalho que, através de uma sequência de etapas definida, parte de um Objetivo [Necessidade] para chegar a um Objeto [Forma]".

Já no âmbito acadêmico, de acordo com Passos et al. (2015), o maior interesse dos docentes deve ser o aprendizado dos alunos. Desse modo, o projeto enquanto processo ganha destaque, uma vez que as metodologias e estratégias adotadas - os meios - para atingir determinados fins são fundamentais. Sobre 0 conceito de projeto no campo do ensino, Chupin (2003) relata que existem muitas contradições em relação ao sentido do termo em escolas europeias e norte-americanas. Na França, por exemplo, o termo é projet, já nos Estados Unidos, design. $\mathrm{O}$ autor defende que projeto é um processo de reflexão e acrescenta que,

[...] dependendo dos ateliês e dos professores, o estudante é levado a considerar seu projeto ora como um resultado (como um objeto), ora como a representação de um resultado (um desenho), mais raramente, como um processo de pensamento conduzido por uma intenção (um desígnio) [...] (CHUPIN, 2003, p.11).

Com relação ao ensino de projeto em arquitetura, Rheingantz (2003) relata que os estudos existentes sobre essa temática reforçam a necessidade de produzir em arquitetura uma pedagogia projetual que seja mais sistematizada, fundamentada e capaz de "substituir a prática guiada pelos temas e programas e pelo determinismo expressivo ou operacional do partido". Silva (1986) defende que o projeto é um tipo de saber que se constrói na realidade, no fazer e na prática, entretanto, o ensino de projeto não é realizado numa prática real, mas sim numa simulação da prática. Para ele, o projeto resulta de um esforço intelectual, um processo que une o sensorial/intuitivo ao racional.

No que se refere ao ensino de projeto em design, conforme afirma Almeida (2009), este ocorre através da apresentação de ferramentas e exemplos. Os componentes curriculares, normalmente, são sequenciais e a complexidade e o poder de decisão do discente aumentam progressivamente. Para Redig (1983), o ensino do design sugere a realização de um projeto como exercício, de forma fictícia.

Diante desse contexto, as disciplinas de projeto, em ambos os cursos analisados, são consideradas de suma importância porque abrangem todos os conteúdos apresentados nas estruturas curriculares. Elas se caracterizam por contemplar conteúdos teóricos e práticos, além de proporcionarem aos alunos uma vivência, ainda que apenas no âmbito acadêmico, que se aproxima da atividade desenvolvida profissionalmente. Por possuírem esse aspecto integrador, existe a necessidade de uma atenção especial dos docentes em como esses conteúdos são ou serão aplicados da prática projetual e se são aplicados (ALMEIDA, 2009). Sobre esse aspecto, Albuquerque (2015, p.13) complementa:

As disciplinas de projeto, como disciplinas integradoras, devem servir como ponto de coesão entre os conteúdos das demais áreas curriculares e a prática projetiva. As disciplinas de ateliê 
são vinculadas à prática profissional e a formação de habilidades específicas para este fim. Estas disciplinas permitirão consolidar a formação acadêmica do estudante, moldando as competências e habilidades.

Silva (2009) relata que, em virtude da natureza destas disciplinas, denominadas pela autora de "promovedoras de vínculos", elas se configuram como o espaço em que variadas contribuições são feitas, de diversas áreas do conhecimento. Essa característica é refletida de forma expressiva nos programas dos cursos, que abordam temas variados e, ao mesmo tempo, comuns a outros componentes curriculares da graduação. A autora ainda defende que a determinação dos conteúdos que serão abordados nas disciplinas de projeto deve incentivar o raciocínio, a discussão e a busca de soluções para problemáticas que se aproximem da realidade, conferindo ao projeto um aspecto dinâmico.

\section{Aproximações conceituais de ateliê}

As disciplinas de projeto são consideradas como a "espinha dorsal"1 dos cursos de Arquitetura e Urbanismo do Brasil e essa realidade também se repete nas graduações de Design de Produto. De acordo com Carsalade (2015), de forma clássica e objetiva, as matérias de projeto normalmente são oferecidas de três maneiras, quais sejam disciplinas convencionais, ateliês de projeto e workshops ou oficinas, sendo esta última uma modalidade mais recente. Em sua tese, Andrade (2011, p.203) conceitua o ateliê acadêmico como:

[...] o centro de toda escola de arquitetura, em torno do qual acontece o encontro entre os sujeitos da aprendizagem e seu objeto. É o locus que abriga a relação entre o estudante e o professor: seu objetivo é a fabricação, como conhecimento em construção, do processo de projeto.

Assim, considerando que o ato de projetar é a principal atividade do designer e do arquiteto, bem como que a universidade, no Brasil, é o local de formação desses profissionais generalistas que tem os ateliês como espaço de realização de tal atividade, é preciso ressaltar que:

[...] desde o espaço físico da sala de aula de projeto - o ateliê (ou estúdio) possuidor de características distintas das salas de aula do ensino tradicional e que o qualificam como espaço de produção - até os procedimentos didáticos das aulas, baseadas nos atendimentos e no trabalho dos estudantes sobre determinados exercícios de projeto, têm qualidades distintas das atividades de ensino convencionais". (VIDIGAL, 2010, p.23, grifo nosso).

Diante desse contexto, junta-se ao ateliê enquanto prática pedagógica, sua realização em espaços apropriados, bem como uma interação entre os envolvidos, de forma que professores e estudantes interajam constantemente em busca de troca de conhecimentos e vivências, com o intuito de analisar as relações que foram criadas no ambiente pedagógico, visualizando questões de caráter mais simbólico e suas formas de manifestação, seja no espaço físico (material) ou no campo mais ideológico, o que representam e como ou de que maneira são apropriadas pelos alunos. Ou seja, "pesquisar a capacidade do ambiente acadêmico em vir a se constituir em forma de representação e lugar da identificação de seus participantes: discentes e docentes" (COLUSSO; HECK, 2015).

$\mathrm{O}$ ateliê de projetos tem o funcionamento diferente quando comparado com as disciplinas universitárias tradicionais, uma vez que nele, durante quase a maior parte do tempo, acontece um processo de ensinoaprendizagem baseado na prática, no fazer projetos (VIDIGAL, 2004). Conforme explica Ochsner (2000 apud VIDIGAL, 2010), o ateliê apresenta problema sem resultados conhecidos e raramente poderá ser comparado a qualquer outra realidade que o aluno já tenha experimentado em algum ambiente educacional. Portanto, levando em consideração que o ensino de projeto é uma atividade prática integradora que trabalha com várias vertentes ao mesmo tempo (reflexão, teoria, história, técnica e etc.), o ateliê precisa ser capaz de realizar essa dinâmica de forma coerente. Colusso \& Heck (2015) caracterizam o ateliê de projeto como um local propício para construção de conhecimento embasado em quatro dimensões: arte, tecnologia, meio ambiente e responsabilidade social. Deste modo, ele não se constitui apenas como um espaço de exercício projetual, mas se propõe a uma atividade de integração de competências. 
Segundo Schön (2000), os ateliês geralmente são dispostos em torno de projetos gerenciáveis de design, que podem acontecer de forma individual ou coletiva e que tendem a reproduzir projetos similares a uma situação real. Conforme o tempo passa, rituais são criados, a exemplo de sessões de avaliação de projetos e apresentações; no entanto, todos estão conectados a um processo central de aprender através do fazer.

Assim como os autores supracitados, considera-se que o ateliê funciona como um espaço de síntese para resolução de problemáticas com base na reflexão e, para isso, o seu espaço físico, bem como os procedimentos metodológicos e pedagógicos nele adotados possuem especificidades. Deste modo, o estudo de caso realizado nos cursos de Arquitetura e de Design da UFCG tem como base dois eixos de abordagem: 1) Infraestrutura do ateliê, que contempla questões referentes ao espaço físico, relacionando-o com a metodologia desenvolvida no ateliê e 2) 0 ensino de projeto, cujo foco é direcionado para a análise dos métodos e recursos adotados, formas de avaliação, formas de uso do espaço e a relação entre professor e aluno. Tais aspectos são defendidos por Masetto (1998) ao caracterizar um ambiente adequado de ensinoaprendizagem superior. $O$ autor destaca cinco pontos fundamentais: a relação entre os participantes do processo (professor e aluno); o espaço físico da aula; a redefinição dos objetivos da aula; a implantação de estratégias participativas e o processo de avaliação.

No primeiro eixo, parte-se do pressuposto de que a infraestrutura disponibilizada nos ateliês influencia diretamente a forma de ensinar, uma vez que, a depender dos equipamentos disponíveis, por exemplo, o professor terá que readequar as estratégias por ele planejadas. Além disso, acredita-se que seja fundamental incentivar a permanência do estudante no ateliê, seja no horário de aula ou não. É interessante que os discentes utilizem o espaço, que, conforme mencionado, deve apresentar as condições necessárias para o desenvolvimento de atividades projetuais. Para tanto, é imprescindível que os ateliês possuam infraestrutura adequada, como, por exemplo: disponibilizem equipamentos eletrônicos; ofereçam mobiliários confortáveis e suficientes; concedam recursos para realização de pesquisa online; disponham de pontos elétricos para conexão de notebooks para realização de trabalhos individuais ou coletivos etc.

Ao relacionar o espaço físico com a metodologia, Colusso e Heck (2015, p.4) assinalam:

\begin{abstract}
Assim, integra-se à proposta do Atelier enquanto prática pedagógica, sua realização em espaços adequados a esta forma de interação no ambiente acadêmico, onde professor e alunos interajam em processo de construção e troca de conhecimentos e vivências buscando observar as relações estabelecidas no ambiente pedagógico, identificando aspectos de conteúdo simbólico e suas formas de manifestação tanto materiais (espaço físico), quanto ideológicas (espaço sociocultural e político), o que representam e de que modo são apropriadas pelos alunos.
\end{abstract}

Com relação ao segundo eixo, é sabido que são muitas as questões que podem ser consideradas no âmbito da metodologia de ensino de projeto. No entanto, no contexto deste artigo, a abordagem será direcionada para aspectos referentes, principalmente, à interdisciplinaridade e integração de conteúdos; métodos adotados pelo professor que possam estimular/facilitar o aprendizado de projeto; formas de avaliação e relação docente/estudante.

Ainda como parte da etapa de conceituação, foi necessário analisar alguns documentos ${ }^{2}$ utilizados como referência no âmbito acadêmico das áreas aqui trabalhadas, sendo eles: Carta da Unesco/UIA para formação em Arquitetura; o documento elaborado pelo MEC - Perfis da área \& Padrões de Qualidade ${ }^{3}$; as Diretrizes Curriculares de cada uma das graduações analisadas e, por fim, os Projetos Políticos Pedagógicos dos cursos pertencentes ao estudo de caso. A análise foi considerada de fundamental importância para compreender, principalmente diante do sistema universitário vigente, como a temática do ateliê de projetos estava inserida e quais pontos inerentes ao tema eram contemplados.

Logo, a partir da junção de tais conceitos e parâmetros apresentados, juntamente com as informações expostas nos documentos e normas que regulamentam e subsidiam o ensino superior tanto em Design, quanto em Arquitetura e Urbanismo, foi possível elaborar uma conceituação própria de ateliê que explora todo o aparato teórico trabalhado até aqui. Esta, conforme pode ser visualizado no esquema abaixo (Figura 2), percebe o ateliê como um espaço de síntese, onde todos os saberes e práticas apreendidos ao longo da vida acadêmica ou não, convergem. É nele que as disciplinas práticas são ministradas e, para isso, faz-se necessário que a carga horária de tais componentes seja elevada. Além disso, acredita-se que os conteúdos que nele são trabalhados devem possuir um objetivo específico. A relação entre os envolvidos deve ser de orientação por parte do professor, devendo este atuar como um instrutor e intermediador do processo de aprendizagem. O estudante, por sua vez, deve participar ativamente deste processo, resultando em um aprendizado individual ou coletivo. 
Figura 2: Parâmetros e conceitos de ateliê.

\section{REFERENCIAL TEÓRICO \\ Ateliê se diferencia dos ensinos convencionais em todos os sentidos. Desde o espaço físico até os procedimentos didáticos adotados. (VIDIGAL, 2010)

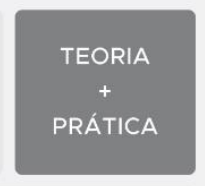
ESPINHA DORSAL Local propício para construção de conheci- mento embasado em quatro dimensões: arte, tecnologia, meio ambien- te e responsabilidade social (HECK e COLUSSO, prático professor atua como instrutor
(SCHÖN, 2000).

\section{DIRETRIZES CURRICULARES}

Art $3^{\circ}$ - O curso de graduação em Design deve ensejar, como perfil desejado do formando, capacitação para a apropriação do pensamento reflexivo e da sensibilidade artística, para que o designer seja apto a produzir projetos que envolvam sistemas de informações visuais, artisticas, estéticas culturais e tecnológicas, observados o ajustamento histórico, os traços culturais e de desenvolvimento das comunidades bem como as características dos usuários e de seu contexto socioeconômico e cultural.

III - Conteúdos teórico-prático: domínios que integram a abordagem teórica e a prática profissional [...] (2004, p.2)

$\S 5^{\circ}$ Os núcleos de conteúdos poderão ser dispostos, em termos de carga horária e de planos de estudo em atividades práticas e teóricas, individuais ou em equipe, tais como: I - aulas teóricas, complementadas por conferências e palestras previamente programadas como parte do trabalho didático regular;

- produção em ateliê, experimentação em laboratórios, elaboração de modelos, utilização de computadores, consulta a bibliotecas e abancos de dados [...] (2010, p. 3)

\section{Carta UIA/UNESCO}

O ratio docentes/estudantes deve refletir a metodologia de ensino de projeto em estúdio/ateliê requerida para obter os conhecimentos e as capacidades atrás indicadas, pois o ensino de projeto deve constituir a parte predominante no processo de formação (2011, p.7).

\section{Perfis da Área \& Padrões de Qualidade}

Atelier (Sala) de Projetos, que não pode ser aceito como resumindo-se a uma sala com pranchetas de desenho, mas que deve ser um espaço de domínio do estudante, onde os temas em andamento possam ser objeto de exposição, de apresentação e discussão de casos. Um espaço que proporcione estas condições nao pode ser compatilhado por outros cursos. (1994, p.7).

\section{PROJETOS POLÍTICOS PEDAGÓGICOS}

O princípio da prática projetual em estúdio configura-se como principio central no Curso de Design da UFCG por atender às seguintes premissas: melhor intercâmbio entre os estudantes; melhor visualização da convergência entre assuntos vistos em disciplinas distintas da grade curricular do curso [...]; Convergência dos assuntos do curso para disciplica Projeto de Produto (2011, p.10)

EIXO PRÁTICO: consiste no foco principal da maioria das disciplinas oferecidas ao longo do curso. As disciplinas [...] são essencialmente de caráter prático, caracterizadas pela

intensidade de aulas de campo, visitas de estudo, aulas de ateliês, atividades em laboratórios, resultando em trabalhos práticos desenvolvidos com base em teorias e metodologias apreendidas em sala de aula, portanto, também apoiadas pelo eixo teórico (2011, p.19)

\section{DISCIPLINA PRÁTICA DE PROJETO COM GRANDE CARGA HORÁRIA}

Conteúdos trabalhados no ateliê possuem um objetivo específico

Alunos desenvolvem exercícios de projeto com auxílio do professor

Os professores atuam como instrutores e intermediadores

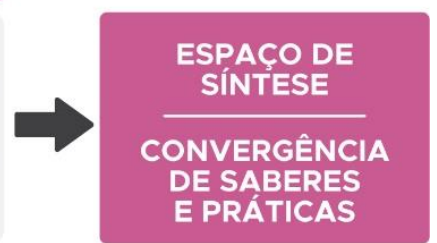

Fonte: Acervo dos autores, 2018.

\section{O ESTUDO DE CASO}

O estudo de caso na UFCG se deu a partir da análise de seis disciplinas, escolhidas segundo os critérios:

- Serem disciplinas com carga horária prática, desenvolvidas em ambiente acadêmico;

- Serem ofertadas em ambiente específico para o desenvolvimento do projeto, tendo este como produto final esperado;

- Por serem componentes curriculares dispostos ao longo dos cursos de graduação selecionados e que apresentam diferentes níveis e graus de complexidade - básico, intermediário e avançado;

- Os componentes curriculares selecionados são os que mais se aproximam no que diz respeito aos períodos letivos que são oferecidos (Figura 3). 
Figura 3: Esquema da escolha das disciplinas de ateliê.

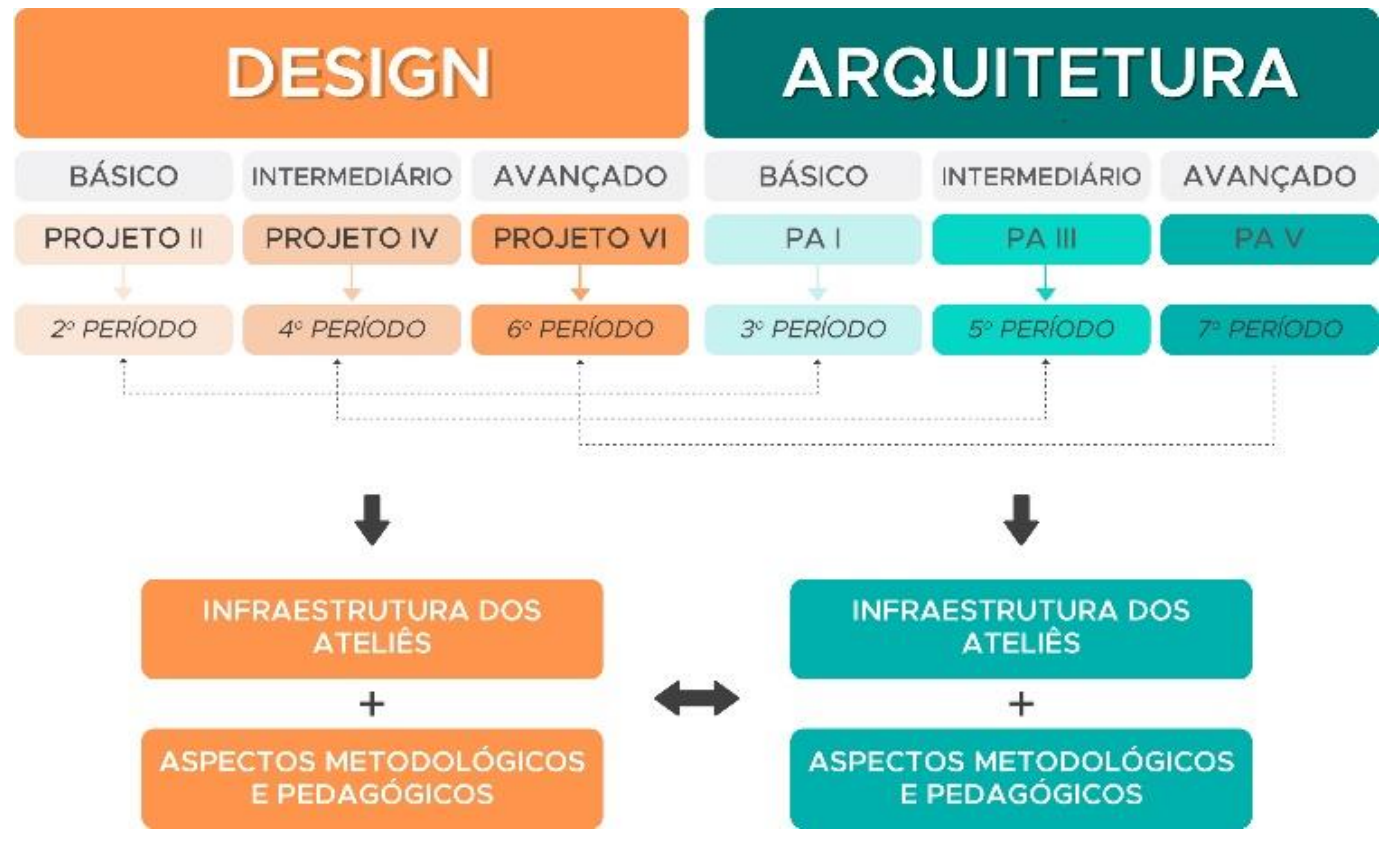

Fonte: Acervo dos autores, 2017.

Após a seleção, a amostra trabalhada foi de 131 estudantes e 6 docentes ${ }^{4}$.

\section{Os ateliês do curso de Design}

As disciplinas de projeto selecionadas para a intervenção - Projeto 2, 4 e 6 - possuíam carga horária de 4h/aula semanais, sendo estas dispostas de forma fragmentada, ou seja, $2 \mathrm{~h} / \mathrm{aula}$ em um dia e $2 \mathrm{~h} / \mathrm{aula}$ em outro dia, com exceção apenas da disciplina de Projeto 4. Em decorrência da pouca quantidade de salas, Projeto 4 e Projeto 6 tinham suas aulas ministradas no mesmo ateliê, ou "Sala de Projeto", como é chamada na Unidade Acadêmica. A disciplina de Projeto 2, por sua vez, era ofertada em uma sala pertencente a um outro bloco da Instituição.

No que se refere ao espaço físico dos ateliês estudados, os dados obtidos através da ficha de observação apresentaram realidades bem parecidas (Figura 4). Com áreas construídas que variam entre 50 e $100 \mathrm{~m}^{2} \mathrm{e}$ formatos retangulares, os ateliês possuíam mobiliários e equipamentos básicos, a exemplo de pranchetas, lousas, bancos altos e baixos, projetor multimídia, computador e birô para o professor e, no caso das disciplinas ofertadas na "Sala de Projetos", um painel destinado para exposição de trabalhos dos discentes. Todavia, nenhum dos ateliês observados possuíam acesso à internet, nem poderiam ser utilizados em horários distintos aos das aulas de projeto.

Ciente de que a permanência do aluno no ateliê também depende bastante da estratégia pedagógica adotada pelos professores, o instrumento aplicado com os docentes contemplava uma questão direcionada para a temática. A partir dos dados coletados, observou-se que, reconhecendo a limitação de utilização do ateliê em horários diversos e opostos ao da aula, os professores se empenhavam para que os alunos permanecessem em sala, mesmo após o assessoramento, através de estratégias diversas. No entanto, as tentativas muitas vezes eram frustradas, uma vez que, ao serem perguntados se costumavam adotar tal postura - de permanecer no ateliê -, a maioria dos estudantes respondeu de forma negativa, usando principalmente a justificativa de que não havia estrutura suficiente e adequada para o desenvolvimento dos projetos - pontos elétricos e acesso à internet principalmente. 
Figura 4: Ateliês analisados no curso de Design - UFCG.

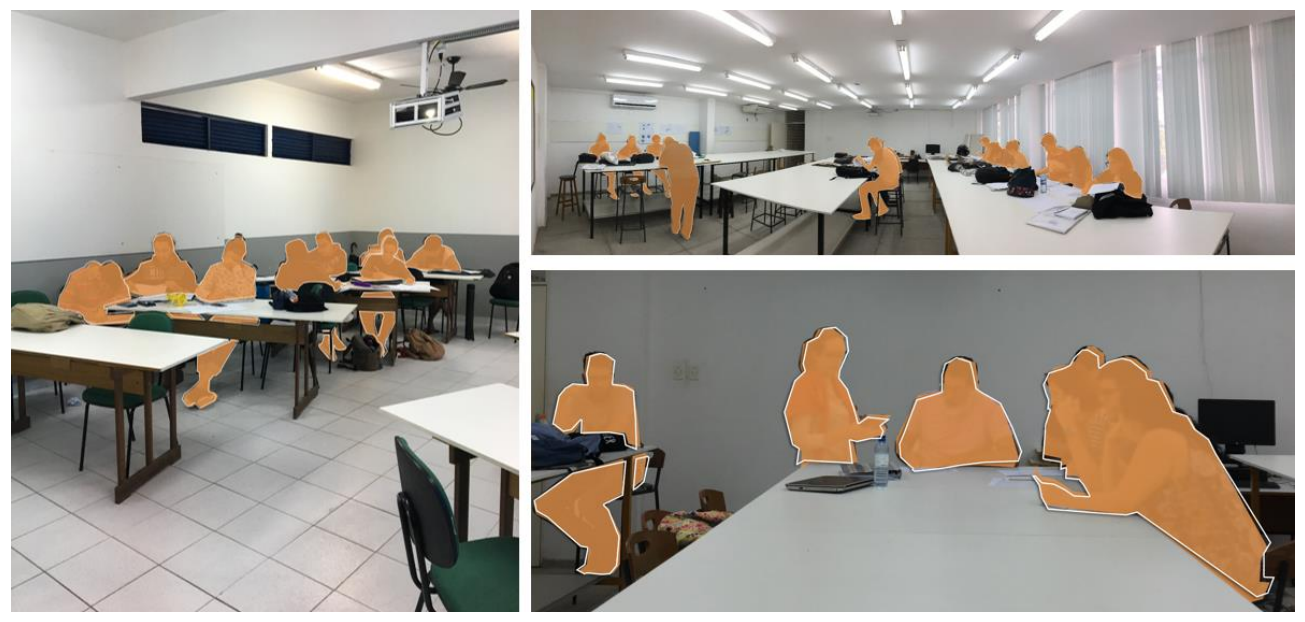

Fonte: Acervo dos autores, 2017.

Ademais, ao longo da tabulação dos dados, um aspecto que não havia sido contemplado diretamente no questionário aplicado com os alunos chamou atenção. Constatou-se, principalmente nos alunos de Projeto 4 e Projeto 6, que os mesmos associavam a falta de interesse em permanecer em sala de aula, em grande parte, à qualidade estética do espaço, a exemplo das cores utilizadas nas paredes e nos mobiliários. Alguns chegaram a dizer, inclusive, que a sala causava um "bloqueio" criativo. O aspecto também foi reconhecido por parte dos professores entrevistados, que alegaram que a falta de criatividade percebida muitas vezes nos alunos era causada, principalmente, pela falta de imagens e informações típicas do design que estimulassem os estudantes de alguma forma nos ateliês. De acordo com os docentes, as salas de projeto não são convidativas:

[...] Eu não entendo como nós, que somos de um curso de Design, temos uma sala assim, tão deficiente em termo de estrutura, porque nós somos do curso de Design, gente! A gente trabalha com cor, a gente trabalha com textura, com imagem, não é? A gente trabalha com todas essas coisas... então são coisas que despertam a pessoa, só que a gente não tem nada disso aqui (Professor 03 - Curso de Design/UFCG).

No que se refere ao ensino de projeto propriamente dito, no item de pré-requisitos necessários ao aprendizado das disciplinas analisadas, embora os alunos considerassem que os possuíam, todos os docentes responderam de forma negativa.

Com relação à integração das disciplinas analisadas com algum outro componente, apenas os docentes de Projeto 2 e Projeto 4 responderam de forma afirmativa. Todavia, na primeira, esta ocorre de maneira parcial, uma vez que a avaliação não é feita conjuntamente e os produtos exigidos também não são os mesmos. $\mathrm{A}$ integração se refere exclusivamente à temática trabalhada, no caso, utensílios de cozinha. Já em Projeto 4 , o professor promove a integração com a disciplina de Ergonomia, também ofertada no mesmo período e ministrada por ele. Nesse caso, a integração igualmente ocorre de forma parcial. O docente de Projeto 6, por outro lado, destacou que embora existam disciplinas interessantes ofertadas no mesmo período e que poderiam integrar-se à que ele ministra, existem dificuldades encontradas por ele principalmente para se encontrar com os demais professores e planejar como se daria tal integração.

Sobre os procedimentos didáticos utilizados pelos professores, verificou-se que em todas as disciplinas analisadas a estratégia mais adotada era a do assessoramento, principalmente na modalidade individual. Em todos os componentes, os professores trabalham apenas com um projeto ao longo do semestre, tendo este entregas parciais de acordo com o calendário da Instituição. Ao fim da disciplina, bem como das unidades, os projetos são todos devolvidos aos alunos.

Quanto à utilização de métodos para o ensino de projeto em Design, todos os professores afirmaram que utilizavam, normalmente, os mais reconhecidos na bibliografia e indicados para o desenvolvimento daquele determinado projeto. No entanto, estes poderiam ser adaptados de acordo com o perfil da turma, a quantidade de alunos e a temática que estava sendo trabalhada. Nas disciplinas em questão, especificamente em Projeto 
2 e Projeto 6, os docentes adotaram métodos para direcionar o processo projetual dos alunos, mas destacaram que, após determinada etapa do processo, deixavam os alunos mais à vontade para definir qual metodologia gostariam de utilizar para desenvolver o trabalho. No caso de Projeto 4, na entrevista com o docente da disciplina, foi constatado que o mesmo adota um método de sua autoria. De acordo com ele, o procedimento para ensino de projeto foi criado há mais de quinze anos e surgiu a partir das necessidades e desafios vivenciados ao longo da sua experiência enquanto professor. Nesse método, que também surge de uma problemática, não existe limite para a quantidade de alternativas que o aluno poderá dar ao projeto, de modo que ele pode chegar a um resultado satisfatório na segunda tentativa, ou, pode precisar fazer dez, vinte, trinta alternativas.

No curso de Design, também foi possível verificar uma ênfase mercadológica, expressa pelos professores e bastante aceita pelos estudantes.

No tocante à avaliação, alunos e professores compartilham o pensamento de que esta deve ser pautada no processo e no produto, tendo o primeiro uma porcentagem maior $(80 \%)$. Ainda sobre essa temática, todos os docentes afirmaram expor os critérios de avaliação previamente com o objetivo de facilitar o desenvolvimento do projeto, bem como das atividades previstas. Na opinião dos alunos, esta é uma conduta totalmente coerente e interfere positivamente no processo projetual. Um aspecto importante sobre esse critério é que, no curso de Design, a avaliação era feita de forma individual pelos professores, aspecto considerado como negativo pelos alunos, pois acreditam que tal estratégia pode melhorar o andamento e o resultado final do projeto.

\section{Os ateliês do curso de Arquitetura e Urbanismo}

Os ateliês escolhidos para a intervenção - Projeto de Arquitetura I, III e V - possuem carga horária de 6h/aula semanais, com exceção apenas do primeiro, que conta com $5 \mathrm{~h} /$ aula semanais. Em todos os casos as horas/aula estavam dispostas de forma fragmentada. Um ponto importante com relação a estas disciplinas e que se diferencia dos componentes curriculares analisados no curso de Design diz respeito à divisão das turmas. Em virtude da grande quantidade de alunos matriculados, em dois dos ateliês selecionados (PA I e III), houve a necessidade de dividir a turma em duas para facilitar as orientações feitas pelo professor.

No que se refere às condições físicas, também são bem parecidas. Eles possuíam áreas construídas que variavam entre $49 \mathrm{~m}^{2}$ e $60 \mathrm{~m}^{2}$, sendo seus formatos retangulares ou quadrados. Quanto aos mobiliários, todos os ateliês se encontravam equipados de pranchetas, cadeiras, bancos, lousa, estantes para exposição de trabalhos e armários coletivos. Além disso, os espaços também contavam com projetor multimídia e alguns poucos pontos de instalações elétricas. Excepcionalmente, em uma das salas, cuja disciplina de PAlll estava sendo ministrada, de área aproximada de $155 \mathrm{~m}^{2}$, verificou-se, além dos mobiliários e equipamentos já mencionados, a existência de algumas máquinas interessantes para os estudos projetuais, quais sejam a máquina de gravação e corte a laser e o túnel de vento. Uma questão importante e que deve ser levada em consideração com relação aos ateliês de Arquitetura e Urbanismo é que, em todos eles, existia a possibilidade de o aluno intervir no espaço, de "se sentir parte", de expor a sua criatividade de alguma forma (Figura 5).

Figura 5: Ateliês analisados no curso de Arquitetura e Urbanismo - UFCG.

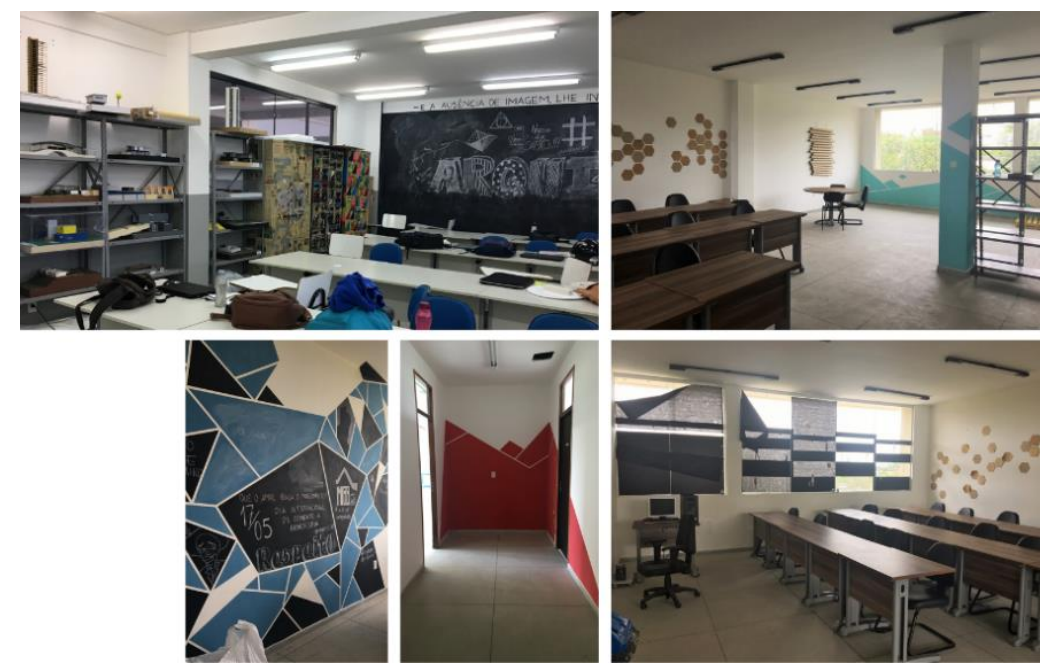

Fonte: Acervo dos autores, 2017. 
Na graduação em Arquitetura e Urbanismo, a permanência dos alunos em ateliê após o assessoramento muitas vezes era prejudicada pela ausência de pontos elétricos e acesso à internet para uso de computadores. Mas, isso não impedia totalmente a sua utilização, visto que os ateliês poderiam ser utilizados em horários distintos aos da aula e foi observado que os alunos permaneciam e frequentavam tais espaços, mesmo diante destas problemáticas que, na opinião dos professores, não se configuram como empecilho para que as atividades planejadas para os componentes curriculares fossem executadas.

Sobre esse aspecto, assim como no curso de Design, os professores costumavam adotar estratégias diversas - rígidas ou mais flexíveis - para incentivar a permanência dos alunos no ateliê, uma vez que a grande maioria dos alunos ainda considera o ateliê o melhor espaço para desenvolvimento das atividades projetuais.

No que se refere ao ensino de projeto propriamente dito, no item de pré-requisitos necessários ao aprendizado das disciplinas analisadas, docentes e estudantes responderam de forma positiva. Quanto à integração da disciplina de projeto com as demais do mesmo período, mesmo os alunos afirmando que conseguiam percebê-la, de forma contraditória e preocupante, quando perguntados sobre a integração dos componentes analisados com alguma outra disciplina da estrutura curricular, todos os professores entrevistados responderam de forma negativa, porém, reconhecendo que, caso tal fato ocorresse, seria de fundamental importância para os alunos e professores envolvidos.

Quanto aos procedimentos didáticos utilizados, foi possível constatar que, em todos os ateliês analisados, a estratégia mais adotada era a do assessoramento, individual ou coletivo (Figura 6). No caso da graduação em Arquitetura e Urbanismo, diferente do curso de Design, percebeu-se que os professores utilizam com bastante frequência o assessoramento coletivo, no qual todos os alunos da turma têm total liberdade de intervir, caso desejem, através de questionamentos, dando dicas ou sugestões para o projeto do colega que está sendo orientado. Na disciplina de PAlll, especificamente, foi possível verificar que o docente também faz uso de exercícios em alguns momentos ao longo do semestre para facilitar o processo de aprendizagem, como, por exemplo, na fase de elaboração de conceitos, estabelecimento de diretrizes projetuais, bem como no processo de avaliação do produto final.

Figura 6: Assessoramentos individuais e coletivos nos ateliês de Arquitetura e Urbanismo - UFCG.
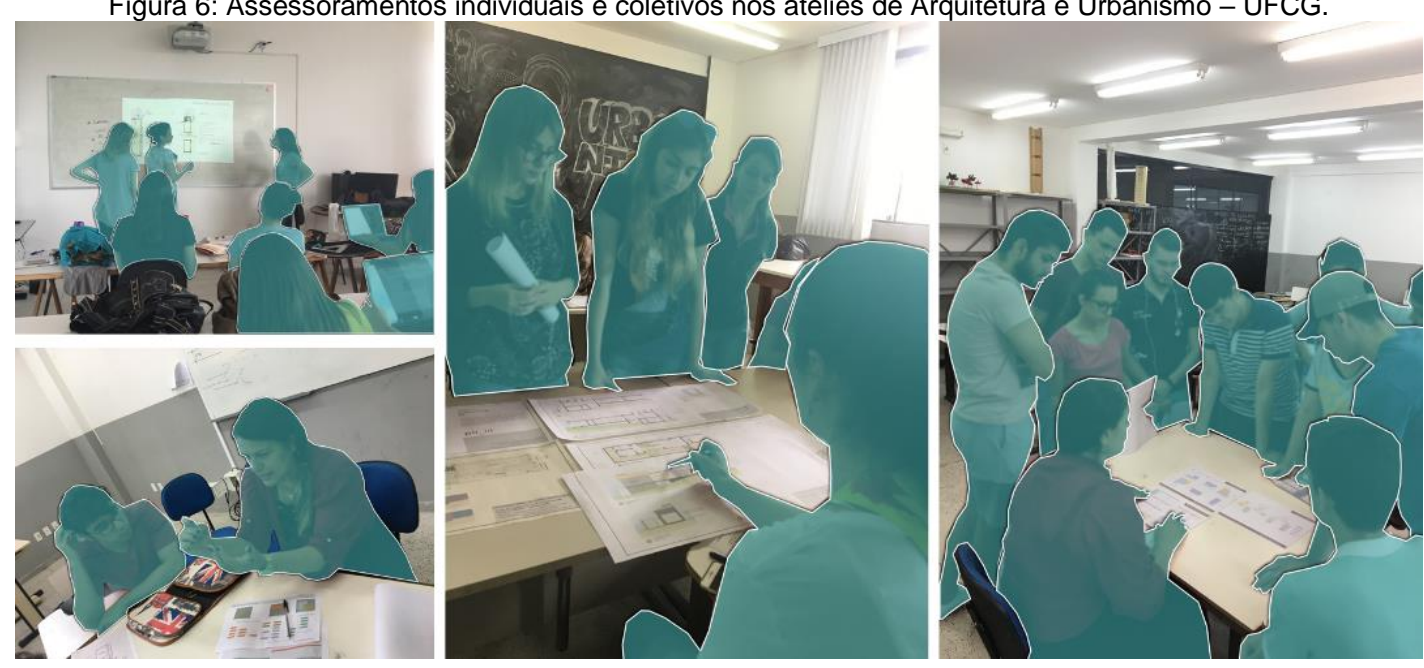

Fonte: Acervo dos autores, 2017

Sobre a utilização de métodos para o ensino de projeto em Arquitetura, os professores afirmaram utilizá-los como forma de dar um norte, uma direção aos alunos. Pôde-se perceber que os docentes das disciplinas de PAI e PAV seguiam procedimentos mais fixos para o desenvolvimento de projetos. No primeiro caso, o método adotado era o da "forma moderna", que, segundo o docente, consiste em retomar critérios projetuais modernos, sendo o projeto arquitetônico uma ferramenta para se criar arquitetura e, portanto, entendido como processo. O professor do componente de PAV trabalha com uma metodologia de intervenção no patrimônio edificado que é alicerçada em outros quatro procedimentos distintos: pesquisa sobre a história da arquitetura (SERRA, 2006); pesquisa para análise arquitetônica (ROVIRA e GÁSTON, 2007); pesquisa de intervenção no patrimônio edificado (KÜHL, 2015) e pesquisa de projeto contemporâneo (PIÑ́́N, 2006).

No caso de Projeto III, o docente adotava uma postura um pouco diferente, deixando os alunos mais livres para decidirem o seu caminho projetual, sugerindo, no entanto, um caminho inicial que pode ser seguido posteriormente pelo discente ou não. Sobre esse aspecto, no que se refere ao procedimento utilizado pelo 
professor de tal componente, o mesmo foi criado por ele há pouco mais de dez anos, inicialmente relacionado exclusivamente ao desenvolvimento de projetos. No entanto, no decorrer da sua vida acadêmica, o mesmo sentiu a necessidade de aplicá-lo como estratégia para ensino de projeto de arquitetura. De acordo com o docente, o método não é absoluto e pode ser adaptado a depender do projeto que está sendo desenvolvido, do perfil da turma, da quantidade de alunos, entre outras condicionantes. Ademais, assim como no curso de Design, os docentes das disciplinas de PAI e PAV também compartilham uma ênfase mais mercadológica na sua prática de ensino de projeto.

No tocante à avaliação, alunos e professores compartilham o pensamento de que esta deve ter como foco o processo (100\% - contínua), uma vez que é dele que surge o produto final. Aqui, os critérios de avaliação também eram previamente expostos pelos docentes, postura totalmente aceita pelos estudantes. Todavia, na graduação em Arquitetura e Urbanismo, a avaliação era feita majoritariamente de forma coletiva, aspecto visto de forma positiva por ambas as partes envolvidas.

\section{Ateliês da UFCG: Especificidades e convergências}

Ao longo da coleta de dados e posterior análise destes, foi possível verificar que as graduações de Design e Arquitetura e Urbanismo possui especificidades, mas, também, diversos pontos de convergência e divergência (Figura 7). Dentre eles, pode-se citar, no tocante ao primeiro eixo - infraestrutura do ateliê aspectos relativos às condições físicas dos espaços e aos recursos disponíveis. Verificou-se que, apesar das limitações encontradas, principalmente com relação ao acesso à internet e, consequentemente, uso das tecnologias formais e informais no ateliê, os professores driblam tais dificuldades através da utilização de estratégias variadas que estimulam a permanência do aluno no ambiente acadêmico e, também, incentivam o aprendizado de projeto.

Com relação ao segundo eixo - o ensino de projeto - constatou-se que, apesar do caráter integrador da disciplina de projeto, esta integração pouco ocorre em ambos os cursos, principalmente devido ao pouco tempo para planejamento da disciplina, bem como problemas de comunicação entre os professores do mesmo curso. Ademais, dois outros pontos importantes e comuns a ambas as graduações se referem à utilização de métodos ou procedimentos para facilitar o ensino de projeto e à ênfase mercadológica trabalhada na grande maioria dos componentes analisados.

Figura 7: Particularidades e semelhanças (em negrito) dos ateliês de Design e de Arquitetura e Urbanismo - UFCG.

\begin{tabular}{|c|c|c|c|}
\hline $\begin{array}{l}\text { INFRAESTRUTURA DO ATELIÊ } \\
\text { LIMITES E POSSIBILIDADES }\end{array}$ & O ENSINO DO PROJETO & $\begin{array}{l}\text { INFRAESTRUTURA DO ATELIÊ } \\
\text { LIMITES E POSSIBILIDADES }\end{array}$ & O ENSINO DO PROJETO \\
\hline $\begin{array}{l}\text { - Espaços retangulares, com } \\
\text { pranchetas e cadeiras; }\end{array}$ & $\begin{array}{l}\text { - Professores exploram a parte } \\
\text { conceitual e técnica do projeto; }\end{array}$ & $\begin{array}{l}\text { - Espaços retangulares, com } \\
\text { pranchetas e cadeiras; }\end{array}$ & $\begin{array}{c}\text { - Alunos possuem todos } \\
\text { os conteúdos de pré-requisitos } \\
\text { necessários; }\end{array}$ \\
\hline - Iluminação natural e artificial; & $\begin{array}{c}\text { - Alunos não possuem todos } \\
\text { os conteúdos de pré-requisitos } \\
\text { necessários; }\end{array}$ & $\begin{array}{l}\text { - Ateliês com espaços para } \\
\text { armazenar material e } \\
\text { expor trabalhos; }\end{array}$ & $\begin{array}{l}\text { - Integração curricular muito } \\
\text { sutil, pontual e } \\
\text { por vezes insuficiente; }\end{array}$ \\
\hline - Falta de acesso a internet; & $\begin{array}{l}\text { - Integração curricular muito } \\
\text { sutil, pontual e } \\
\text { por vezes insuficiente; }\end{array}$ & $\begin{array}{c}\text { - Ateliês com equipamentos } \\
\text { que viabilizam a realização } \\
\text { de trabalhos: }\end{array}$ & $\begin{array}{l}\text { - Assessoramento individual } \\
\text { e coletivo; }\end{array}$ \\
\hline $\begin{array}{l}\text { - Ateliês só podem ser utilizados } \\
\text { nos horários das aulas; }\end{array}$ & - Assessoramento individual; & $\begin{array}{l}\text { - Possibilidades de intervenção } \\
\text { artísticas livre nos espaços; }\end{array}$ & $\begin{array}{l}\text { - Utilização de métodos para } \\
\text { nortear o ensino do projeto; }\end{array}$ \\
\hline $\begin{array}{l}\text { - Maioria dos alunos não } \\
\text { permanecem em } \\
\text { sala após a orientação; }\end{array}$ & $\begin{array}{l}\text { - Utilização de métodos para } \\
\text { nortear o ensino do projeto; }\end{array}$ & - lluminação natural e artificial; & - Ênfase mercadológica; \\
\hline \multirow{7}{*}{$\begin{array}{l}\text { - Professores adotam } \\
\text { estratégias diversas para } \\
\text { estimular a permanência } \\
\text { do aluno no ateliê. }\end{array}$} & - Ênfase mercadológica; & - Pontos elétricos insuficientes; & \multirow{2}{*}{$\begin{array}{l}\text { - Utilização de tecnologias } \\
\text { formais e informais, } \\
\text { mesmo com as limitaçốes; }\end{array}$} \\
\hline & \multirow{2}{*}{$\begin{array}{l}\text { - Utilização de tecnologias } \\
\text { formais e informais, } \\
\text { mesmo com as limitações; }\end{array}$} & - Falta de acesso a internet: & \\
\hline & & \multirow{2}{*}{$\begin{array}{l}\text { - Ateliês podem ser utilizados em } \\
\text { horários opostos aos das aulas; }\end{array}$} & \multirow{2}{*}{$\begin{array}{l}\text { Avaliação individual e/ou coletiva } \\
\text { e com maior porcentagem } \\
\text { para o processo; }\end{array}$} \\
\hline & \multirow{2}{*}{$\begin{array}{l}\text { - Avaliação individual e } \\
\text { com maior porcentagem } \\
\text { para o processo; }\end{array}$} & & \\
\hline & & & \multirow{2}{*}{$\begin{array}{c}\text { - Alunos aceitam críticas, confiam } \\
\text { nas orientações do professor e, } \\
\text { em alguns momentos, adotam } \\
\text { postura crítica. }\end{array}$} \\
\hline & \multirow{2}{*}{$\begin{array}{l}\text { - Alunos aceitam críticas, confiam } \\
\text { nas orientações do professor, } \\
\text { mas demostram insegurança com } \\
\text { relação ao seu processo projetual. }\end{array}$} & em sala após a orientação; & \\
\hline & & $\begin{array}{l}\text { - Professores adotam } \\
\text { estratégias diversas para } \\
\text { estimular a permanência } \\
\text { do aluno no ateliê. }\end{array}$ & \\
\hline
\end{tabular}

Fonte: Acervo dos autores, 2018. 
No que se refere à relação entre professor e aluno, sob uma perspectiva mais quantitativa, foi possível verificar que a grande maioria dos ateliês analisados não se enquadra totalmente nos padrões exigidos pelo MEC no documento "Perfis da Área \& Padrões de Qualidade". Este, embora se refira primordialmente ao curso de Arquitetura e Urbanismo, também pode ser aplicado aos cursos de Design, já que ambos possuem componentes destinados ao ensino prático de projeto. O documento estabelece, no tocante aos requisitos para abertura e funcionamento dos cursos:

Quadro qualificado e em número suficiente para que seja respeitada a relação professor / aluno de:

a) aula teórica - 1:30

b) aula prática e de projeto - 1:15 (SILVA et al., 1994, p.13).

A partir de uma abordagem mais qualitativa, os resultados demonstraram que, no curso de Design, embora os professores permitissem um livre acesso para comunicação, estes também alegaram que sentiam um certo distanciamento por parte dos alunos. Acredita-se que o fato decorre da insegurança que os discentes tinham no seu processo projetual, resultando, muitas vezes, no medo de chegar ao professor para conversar sobre assuntos relativos à disciplina ou não. Na graduação em questão, foi possível verificar que, nos momentos de assessoria, a maioria dos alunos não costumava adotar uma postura crítica ou de defesa das ideias apresentadas em seu projeto. Eles aceitavam as sugestões, apreciações e confiavam nos (re) direcionamentos apontados pelos professores, mas, raramente, questionavam ou defendiam as suas próprias soluções projetuais. Certamente, em virtude desse distanciamento apontado pelos professores, percebido pelos alunos e observado na análise dos dados.

Uma realidade diferente, em alguns aspectos, foi constatada na graduação em Arquitetura e Urbanismo. No que se refere à relação professor-alunos, estes últimos costumavam aceitar as sugestões e críticas feitas pelos docentes no assessoramento, bem como adotavam um posicionamento de defesa das ideias, apesar de confiarem nos direcionamentos apontados pelo professor. Quanto à posição dos docentes, percebeu-se que estes permitiam um espaço aberto, livre, baseado no respeito entre as partes envolvidas. Em alguns casos, inclusive, os professores mantinham contato online com os alunos via redes sociais para facilitar a comunicação e promover a aproximação entre ele e os estudantes. De uma forma geral, em ambos os cursos analisados, foi possível verificar que os professores reconheciam que no ateliê a relação era de aprendizado mútuo, onde ambos aprendem e compartilham experiência. Para isso, torna-se fundamental que o docente atue como mediador do processo de aprendizagem, utilizando o ateliê para interação entre ele e os alunos e como um espaço que proporcione a resolução de problemas a partir do conceito de reflexão na ação.

\section{CONSIDERAÇÕES FINAIS}

A partir do levantamento realizado no referencial teórico e na pesquisa de campo nos ateliês de projeto de Design e de Arquitetura da Universidade Federal de Campina Grande, percebeu-se que o ateliê, enquanto espaço de síntese do aprendizado, necessita de reflexão por parte dos docentes e das Instituições de Ensino Superior, no tocante não apenas à infraestrutura e aos recursos disponibilizados, mas também com relação às práticas pedagógicas e didáticas nele existentes.

Nas graduações analisadas, pôde-se verificar que as disciplinas de ateliê compartilham semelhanças no tocante ao desenvolvimento de fundamentos conceituais e metodológicos para o projeto; às estratégias de ensino adotadas; e à estruturação de maneira sequencial, acompanhando todas as fases da formação do aluno e tendo a sua complexidade aumentada à medida em que ele evolui na graduação.

É notório, deste modo, que o ato de ensinar o projeto, conforme constatado desde as escolas precursoras até as práticas mais atuais, envolve diversas singularidades e particularidades, relacionadas desde o espaço físico disponível até as estratégias pedagógicas adotadas pelos professores para tal fim. É preciso entender que a organização de métodos, procedimentos e conteúdos é importante para que a aula faça sentido e seja consistente dentro da formação dos educandos. Ciente de que um fator interfere no outro e vice-versa, é necessário ressaltar que o projeto, em Design e em Arquitetura e Urbanismo, abrange a assimilação de conteúdos e de ideias que possam se relacionar, ou seja, alinhar-se e integrar-se. Portanto, acredita-se que tais procedimentos devem estimular o desenvolvimento contínuo da criatividade e da capacidade reflexiva e crítica dos futuros designers e arquitetos. Para isso, é de fundamental importância que os conteúdos trabalhados no ambiente de síntese e de grande carga horária - ateliê - possuam um objetivo específico e sejam desenvolvidos entre alunos e professores. Além disso, como parte do conceito de ateliê aqui defendido e elaborado, é de extrema importância que tais componentes práticos se integrem com os demais existentes 
nas estruturas curriculares, o que é totalmente possível quando se compreende que a variedade de contribuições de outras áreas do conhecimento é essencial no ensino-aprendizagem de projeto.

No que se refere às questões avaliativas nesse tipo de ensino, foi possível concluir, a partir da pesquisa de campo, norteada por categorias analíticas, que a exposição dos conteúdos, métodos e objetivos da disciplina são fundamentais na evolução do processo de ensino-aprendizagem. Do ponto de vista pedagógico, acreditase que é de responsabilidade do professor atuar como intermediador, estimulando o aluno a pensar criticamente sobre o seu trabalho, enfatizando as suas potencialidades e o redirecionando caso seja necessário. Além da autocrítica, é importante estimular a percepção crítica do aluno perante os projetos dos outros estudantes da turma, uma vez que muito se aprende ao ter contato com a forma de pensar das outras pessoas.

Por fim, o estudo possibilitou a percepção de que as áreas aqui constatadas visam à criação de um novo objeto (de diferentes escalas), materializado a partir do projeto, que compreende uma série de conhecimentos teóricos, práticos e metodológicos a fim de obter-se uma produção adequada, coerente e criativa. Deste modo, acredita-se que, além de viabilizar a integração vertical e horizontal nos cursos analisados, outra possibilidade seria promover o maior vínculo entre os dois campos de atuação, principalmente para que as questões comuns, os pontos de convergência entre as graduações, sejam aperfeiçoados e otimizados, visando ao melhoramento da qualidade do ensino, bem como a integração, desde a formação, de duas áreas do conhecimento que têm o projeto como um dos seus principais objetivos. Sabe-se, todavia, que a adoção de tais estratégias e a inclusão destes processos nos programas de ensino só ocorrerão se isto estiver em conformidade com os interesses propostos pelos cursos, expostos através dos seus Projetos Político Pedagógicos e suas estruturas curriculares.

\section{REFERÊNCIAS}

ALBUQUERQUE, C. C. G. Reestruturação pedagógica e curricular: o caso do curso de Arquitetura e urbanismo da Universidade de Fortaleza (UNIFOR). 2015. XVII CONABEA e XXXVII ENSEA, Universidade Federal do Rio Grande do Norte.

ALMEIDA, R. R. Estudo de público-alvo em Design. Abordagem de aspectos subjetivos do usuário em disciplinas de projeto de produto. 2009. Dissertação (Mestrado em Design) - Universidade Federal de Pernambuco. Recife, 2009.

ANDRADE, L. M. V. Construção e abertura: Diálogos Christopher Alexander - Jean Piaget. 2011. 443 pg. Tese (Doutorado). Universidade Federal do Rio Grande do Sul. Porto Alegre, Agosto de 2011.

BRASIL. Ministério da Educação. Conselho Nacional de Educação. Câmara de Educação Superior. Resolução № 2, de 17 de Junho de 2010. Institui as Diretrizes Curriculares Nacionais do curso de graduação em Arquitetura e Urbanismo, alterando dispositivos da Resolução CNE/CES no 6/2006. Diário Oficial da União de 18/06/2010, Seção 1, pp. 37-38.

BRASIL. Ministério da Educação. Conselho Nacional de Educação. Câmara de Educação Superior. Referencial para as Diretrizes Curriculares Nacionais - DCN dos Cursos de Graduação. CNE/CES no 67/2003. Diário Oficial da União de $13 / 05 / 2002$.

CARSALADE, F. L. A inovação pedagógica do PFLEX na UFMG: considerações sobre a disciplina e estudo de caso. 2015. PROJETAR 2015, Universidade Federal do Rio Grande do Norte.

COLUSSO, I.; HECK, A. Novas práticas pedagógicas no curso de Arquitetura e Urbanismo da Unissinos: 0 atelier de projeto e a rede Mercosul. 2015. PROJETAR 2015, Universidade Federal do Rio Grande do Norte.

CONFEA. Trajetória e estado da arte da formação em engenharia, arquitetura e agronomia / Conselho Federal de Engenharia, Arquitetura e Agronomia. - Brasília: Instituto Nacional de Estudos e Pesquisas Educacionais Anísio Teixeira; Conselho Federal de Engenharia, Arquitetura e Agronomia, 2010.

COX, L. et al. A Carta UNESCO/UIA: PARA A FORMAÇÃO EM ARQUITETURA. 2011. Comissão de Formação do Arquiteto da UIA. Disponível em: http://www.cialp.org/documentos/1439567302V4pFQ3qn3Jd55EK0.pdf. Acesso em: setembro/2017.

LAWSON, B. Como arquitetos e designers pensam. Oficina de Textos, São Paulo; 4ª edição, 2011.

PASSOS, L. A.; SILVA, H. A.; FERNANDES, C. C. Recursos digitais e o processo projetual paisagístico. Educação Gráfica (Online), v. 19, p. 353-370, 2015.

PPP ARQUITETURA E URBANISMO UFCG. Projeto Político Pedagógico do Curso de Arquitetura e Urbanismo. Universidade Federal de Campina Grande. Centro de Ciências e Tecnologia. Unidade Acadêmica de Engenharia Civil. Dezembro de 2011.

PPC DESIGN UFCG. Projeto Político Pedagógico do Curso de Design. Universidade Federal de Campina Grande. Centro de Ciências e Tecnologia. Unidade Acadêmica de Desenho Industrial. Março de 2011. 
REDIG, J. Sentido do Design. Rio de Janeiro: Imprinta, 1983.

REDIG, J. Sobre desenho industrial [ou design] e desenho industrial no Brasil. 2. ed. Porto Alegre:: Editora UniRitter, 2005, s/n.

RHEINGANTZ, P. A. Arquitetura da autonomia: bases pedagógicas para a renovação do atelier de projeto de arquitetura. IN: LARA, F.; MARQUES, S. (org.) Projetar- Desafios e Conquistas da Pesquisa e do Ensino. Rio de Janeiro: Editora Virtual Científica, 2003.

SCHÖN, D. A. Educando o profissional reflexivo: Um novo design para o ensino e a aprendizagem. Porto Alegre: Artmed, 2000.

SILVA, H. A. Projeto em Áreas Consolidadas de Patrimônio Cultural: propostas para a construção de uma metodologia de ensino. 2012. 395 f. Tese (Doutorado em Arquitetura e Urbanismo) - Curso de Programa de Pósgraduação em Arquitetura e Urbanismo, Universidade Federal do Rio Grande do Norte, Natal, 2012.

SILVA, E. Sobre a Renovação Do Conceito de Projeto Arquitetônico e sua Didática. In: COMAS, Carlos Eduardo (organizador), Projeto Arquitetônico: Disciplina em crise. Disciplina em Renovação. São Paulo: CNPq, 1986.

SILVA, I. M. L. Arquitetura e Design: Os conteúdos que acercam seus programas de ensino. 2009. Dissertação (Mestrado em Arquitetura e Urbanismo) - Universidade São Judas Tadeu, 2009.

SILVA, E.; KALIL, I.; MAGALHÃES, M. A. A. A.; SILVEIRA, R. P. G.; FICHER, S. Perfis da área \& padrões de qualidade - expansão, reconhecimento e verificação periódica dos cursos de arquitetura e urbanismo. Brasília, Ceau/Sesu, 1994. Disponível em: http://portal.mec.gov.br/sesu/arquivos/pdf. Acesso em maio/2017.

VIDIGAL, E. J. Ensino de projeto arquitetônico: um estudo sobre as práticas didáticas no curso de au da uf do paraná. 2011. 350 pg. Tese (Doutorado). Universidade de São Paulo. São Paulo, 14 de dezembro de 2010.

CHUPIN, J. As Três Lógicas Analógicas do Projeto em Arquitetura: do impulso monumental à necessidade de pesquisa passando pela inevitável questão da "ensinabilidade" da arquitetura. In: LARA, F.; MARQUES, S. (Orgs.). Desafios e conquistas da pesquisa e do ensino de projeto. Rio de Janeiro: EVC, 2003. pp.11-31.

BOUTINET, Jean-Pierre. Antropologia do Projeto. 5. Ed. Porto Alegre: Artmed, 2002.

PIÑÓN, H. Entrevista. In: Vitruvius, 043.03, ano 11, set 2010. Entrevista concedida ao Vitruvius no dia 25 de novembro de 2009 aos entrevistadores Magdalena Reches e Julio Cesar Diarte. Disponível em: https://goo.gl/J101UE. Acesso em nov/2016.

FERRARA, L. D. A. Design em espaços. São Paulo: Rosari, 2002.

\section{NOTAS}

${ }^{1}$ Em 1957, sob supervisão dos professores Abelardo Souza, Hélio Duarte, Vilanova Artigas e Rino Levi, houve uma reforma na estrutura curricular do curso de Arquitetura e Urbanismo da Universidade de São Paulo. A mudança se justificava pela pouca importância dada à "composição arquitetônica" no quadro do ensino. Deste modo, os profissionais sugeriram uma nova estrutura que tinha o "atêlier" como espinha dorsal do curso, com os demais componentes curriculares para ele convergindo. Diante desse contexto, foi implantada na FAU/USP uma estrutura curricular com quatro áreas de interesse: Comunicação Visual, Desenho Industrial, Edifício e Urbanismo (CONFEA, 2010, p. 64).

${ }^{2}$ Os dois primeiros documentos se referem exclusivamente a graduação em Arquitetura e Urbanismo, no entanto, no contexto deste artigo e mediante o referencial teórico exposto, acredita-se que as questões neles trabalhadas, principalmente no que se refere ao ensino de projeto e o ateliê, se aplicam as duas áreas de atuação aqui contempladas.

${ }^{3}$ Documento elaborado pelo MEC em 1994 para auxiliar na criação e avaliação dos cursos de graduação em Arquitetura e Urbanismo.

${ }^{4}$ Os procedimentos metodológicos de aplicação de questionário com os estudantes e de entrevistas semiestruturadas com os docentes só foram iniciados após a aprovação via pareces consubstanciado do Comitê de Ética e Pesquisa da UFCG (CAAE: 70431817.0.0000.5182).

NOTA DO EDITOR (*) O conteúdo do artigo e as imagens nele publicadas são de responsabilidade do(s) autor(es). 